\title{
Morphologic Basis for Developing Diverticular Disease, Diverticulitis, and Diverticular Bleeding
}

\author{
Thilo Wedel Martina Barrenschee Christina Lange François Cossais Martina Böttner \\ Institute of Anatomy, Christian-Albrechts-University of Kiel, Kiel, Germany
}

\section{Keywords}

Diverticular disease . Connective tissue .

Enteric nervous system · Enteric musculature .

Intestinal motility

\section{Summary}

Diverticula of the colon are pseudodiverticula defined by multiple outpouchings of the mucosal and submucosal layers penetrating through weak spots of the muscle coat along intramural blood vessels. A complete prolapse consists of a diverticular opening, a narrowed neck, and a thinned diverticular dome underneath the serosal covering. The susceptibility of diverticula to inflammation is explained by local ischemia, translocation of pathogens due to retained stool, stercoral trauma by fecaliths, and microperforations. Local inflammation may lead to phlegmonous diverticulitis, paracolic/mesocolic abscess, bowel perforation, peritonitis, fistula formation, and stenotic strictures. Diverticular bleeding is due to an asymmetric rupture of distended vasa recta at the diverticular dome and not primarily linked to inflammation. Structural and functional changes of the bowel wall in diverticular disease comprise: i) Altered amount, composition, and metabolism of connective tissue; ii) Enteric myopathy with muscular thickening, deranged architecture, and altered myofilament composition; iii) Enteric neuropathy with hypoganglionosis, neurotransmitter imbalance, deficiency of neurotrophic factors and nerve fiber remodeling; and iv) Disturbed intestinal motility both in vivo (increased intraluminal pressure, motility index, high-amplitude propagated contractions) and in vitro (altered spontaneous and pharmacologically triggered contractility). Besides established etiologic factors, recent studies suggest that novel pathophysiologic concepts should be considered in the pathogenesis of diverticular disease.

\section{Diverticular Disease - A Common Condition with a Neglected Pathogenesis}

Diverticular disease ranges among the most common benign diseases of the gastrointestinal tract. Due to its high prevalence especially in the elderly, diverticular disease represents the 5th most important gastrointestinal disease in Western countries in terms of direct and indirect costs with a mortality rate of 2.5 per 100,000 population per year [1]. In spite of its worldwide distribution and socioeconomic impact, the pathogenesis of diverticular disease is not yet fully understood, and most literature data on this issue date back to the 1960/70/80ies. In fact, a search in medical databases (e.g. Ovid/PubMed) reveals that much more efforts have been made to unravel pathogenetic factors for inflammatory bowel diseases (10-fold), arterial hypertension (50-fold), and diabetes mellitus (60fold) compared to diverticular disease in terms of available studies.

Thus, in spite of being a major healthcare problem with currently changing concepts of classification, diagnostic procedures, and clinical management as evidenced by the release of current guidelines [2], the pathogenesis of diverticular disease appears to be a rather neglected research field deserving more attention. Here, we provide an overview of the pathomorphologic peculiarities of developing colonic diverticula, the spectrum of complications arising from diverticulitis, and the mechanisms underlying diverticular bleeding. In particular, both traditional and novel concepts in regard to the pathogenesis of diverticular disease are addressed.

\section{Definition of Colonic Diverticula}

The Latin term 'deverticulum' signifies a sideway or hide-out. The medical term describes a local and abnormal outpouching of a hollow organ. While 'true' diverticula involve all layers of the organ wall, 'false' diverticula are limited to an outbulging of only the inner layers, therefore also termed pseudodiverticula. In contrast to duodenal and jejunal diverticula or Meckel's diverticulum, co-

\section{KARGER \\ Fax +497614520714


Fig. 1. a Macroscopic features of diverticular disease illustrated by a colonic specimen with two complete, stoolfilled diverticula. Note the narrowed diverticular neck and the thinwalled, distended diverticular dome only covered by serosa and epiploic fat. The colonic wall is considerably constricted and the muscle coat is thickened. b Histological features of diverticular disease are characterized by mucosal/submucosal outpouchings which herniate through the muscle coat along connective tissue sheaths surrounding transmural vessels
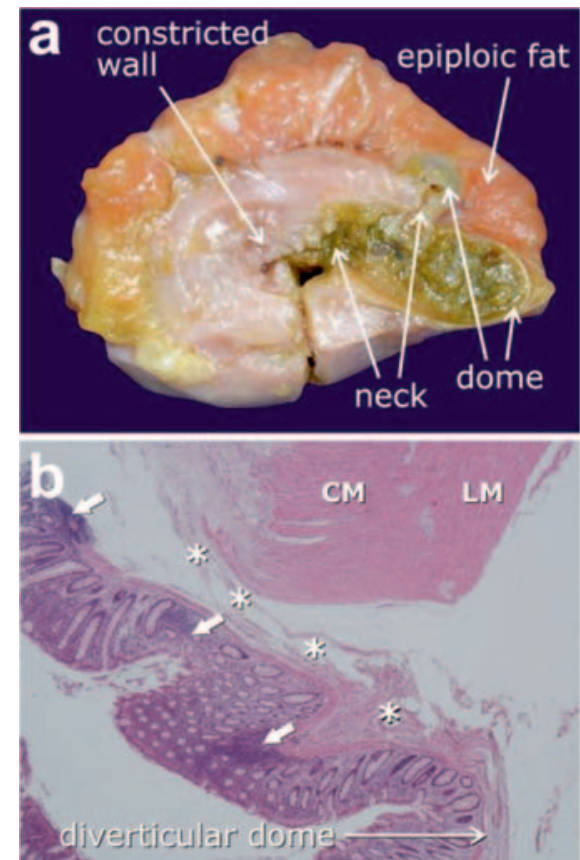

(asterisks). Initial signs of inflammation include cryptitis, crypt distortion, mucosal ulcerations, and peridiverticular inflammatory infiltrates (arrows). Hematoxylin \& eosin staining, magnification $\times 10 . \mathrm{CM}=$ Circular muscle layer; $\mathrm{LM}=$ longitudinal muscle layer. Fig. 1a kindly provided by Imke Weyers, MD, Institute of Anatomy, University of Lübeck, Germany.

lonic diverticula are classified as pseudodiverticula affecting the mucosal and submucosal layer. Whereas complete pseudodiverticula penetrate through the entire muscle layer and reach the serosal covering, incomplete pseudodiverticula are defined by a herniation which is arrested within the muscle layer [3].

A complete colonic pseudodiverticulum is composed of the following parts (fig. 1a):

- diverticular opening: the luminal portal through which the mucosal/submucosal herniation takes place;

- diverticular neck: the segment which passes through the muscle coat and is frequently narrowed due to muscular contraction;

- diverticular fundus: the extramurally located dome underneath the serosal covering which only comprises the thinned and distended mucosal/submucosal layer.

In the clinical jargon, however, the term colonic pseudodiverticula has been replaced by colonic diverticula. Although incorrect by definition, we stick to this convention in the following.

\section{Morphologic Basis for the Development of Colonic Diverticula}

The colonic wall consists of an inner mucosal and outer muscular layer separated by the submucosal layer allowing shift motions between the inner and outer tube. The high mobility and abundancy of mucosal tissue are prerequisites for the susceptibility to slip over a rather large distance from the luminal surface into and through the muscle coat. Moreover, in contrast to the esophagus, stomach, and small intestine, the longitudinal muscle in the colon does not form a continuous layer but is instead reduced to three parallel running muscle bands (taeniae coli), which predisposes to the preferential development of diverticula in colonic segments of the gastrointestinal tract. Of note is the observation that diverticula do not develop in the rectum - the region in which the three separate taeniae fuse again to make up a continuous longitudinal muscle layer.

Predilection sites of prolapsing mucosal/submucosal tissue are preformed weak points (loci minoris resistentiae) within the muscle coat where blood vessels enter the colonic wall. These so-called vasa recta arise from the mesenteric vascular arcades, penetrate through muscular gaps, and reach the submucosa and mucosa providing blood supply. Herniation of diverticula occurs along the perivascular connective tissue envelope which surrounds the intramurally located vasa recta and functions as gliding channel. The dense distribution of vasa recta in the left colon, in particular along the sigmoid segment, may explain the high frequency of diverticula in this region $[4,5]$.

\section{Location of Colonic Diverticula}

Colonic diverticula are most commonly found in the sigmoid colon (approximately 90\%) followed by the descending colon and less frequently by the transverse and ascending colon. With increasing age, the development of diverticula tends to spread from distal to more proximally located sites. Whereas in Western countries right-sided diverticula are only seldom observed, in Eastern countries diverticula develop preferentially along the right hemicolon (approximately 70\%) [6, 7]. In general, right-sided diverticula are more common in younger people and more predominant in men [8]. In principal, the pathomorphologic mechanisms underlying the development of right-sided diverticula are similar to those of left-sided diverticula $[9,10]$. The varying location has been attributed to differences in morphology (e.g. length, thickness) and functional parameters (e.g. intraluminal pressure, prolonged transit time) of the colon, rather than to environmental differences.

\section{Pathomorphologic Events Leading from \\ Diverticulosis to Diverticular Disease}

Most individuals with colonic diverticula do not develop symptoms during their entire life time (approximately 80\%) - a condition defined as asymptomatic diverticulosis. However, the remaining patients will experience complications arising from 'cold' diverticula which comprise different types/severity grades of diverticulitis and/or diverticular bleeding.

\section{Diverticulitis}

The vulnerability of colonic diverticula to inflammatory events is explained by the following pathomorphologic and pathophysiologic mechanisms: 
- Submucosal blood vessels are pulled into the diverticulum and, thus, become distended and compressed. Local ischemia of the herniated mucosa resulting from the decreased blood supply increases the risk of inflammation.

- Due to the frequently narrowed diverticular neck, retained stool cannot be emptied from the diverticular sac. Exposure time to intraluminal bacteria is increased and favors translocation of pathogenic germs.

- The entrapped stool can transform into a fecalith of harder consistency able to mechanically irritate the mucosal lining resulting in a 'stercoral trauma' of the epithelial lining.

- The diverticular fundus is frequently distended and thin-walled. Due to the weakened resistance, microperforation can easily take place, in particular at the diverticular fundus, allowing inflammatory spread into pericolic tissues and abscess formation. The initial inflammatory histopathologic features of diverticulitis are prominent mucosal folds with mild cryptitis, crypt distortion, mucosal ulcerations, and periostal inflammatory infiltrates composed of lymphocytes, neutrophils, and activated macrophages [11-13] (fig. 1b). The local inflammatory process (peridiverticulitis) can spread transmurally to adjacent colonic segments (phlegmonous diverticulitis) and may result in different types of complications, e.g. microabscess, paracolic/mesocolic abscess, covered or open bowel perforation, purulent or fecal peritonitis. Fistula formation and stenotic strictures are particularly triggered by recurrent chronic forms of diverticulitis [13].

Overlaps of histopathologic findings between diverticulitis and inflammatory bowel diseases have been described in diverticular specimens, e.g. the presence of granuloma, transmural inflammatory infiltrates, lymphoid aggregates, or Paneth cell metaplasia [14]. It has been suggested that the presence of Crohn's disease in association with diverticulosis predisposes to the development of diverticulitis. In rare cases (approximately 1\%), segmental colitis is associated with sigmoid diverticula (SCAD) in which the inflammatory changes are not confined to peridiverticular regions but found along the entire diverticula-bearing colonic segment $[13,15,16]$.

\section{Diverticular Bleeding}

Colonic diverticula are a common source for lower gastrointestinal bleeding, in particular in the elderly. Bleeding from diverticula may be occult or massive, but will stop spontaneously in approximately $90 \%$ of the patients. Although most diverticula develop in the sigmoid colon, diverticular bleeding occurs at least half of the time in the right colon suggesting higher susceptibility of this colonic segment to diverticular hemorrhage. The bleeding is due to a rupture of intramurally located vasa recta. The following pathomorphologic peculiarities of the angioarchitecture have been described $[17,18]$ :

- Due to the mucosal/submucosal herniation, the vasa recta are bent, distended, and shifted into close proximity to the luminal surface, thereby increasing its mechanical vulnerability.

- Rupture of the blood vessel is asymmetric and eccentric, pointing towards the lumen of the diverticular dome.
- At the bleeding point, eccentric thickening of the tunica intima and duplication of the lamina elastic interna are observed suggesting intimal proliferation due to traumatic factors, e.g. 'stercoral trauma' by impacted fecaliths.

Of note is the observation that in most cases bleeding diverticula are not simultaneously affected by inflammatory infiltrates, thus ruling out inflammatory events as primary pathogenetic factors for diverticular bleeding. Conversely, factors which are known to alter the blood flow and/or the angioarchitecture, e.g. anticoagulatory medication, arterial hypertension, ischemic heart disease, and diabetes mellitus, are associated with an increased risk of diverticular bleeding. Recently, obesity has been identified as an additional risk factor for diverticular hemorrhage, although the exact pathomechanism is not yet clear. It is suggested that both the angioarchitecture and the connective tissue envelope of vasa recta are altered with increasing visceral fat deposits [19].

\section{Structural and Functional Alterations of the Bowel Wall in Diverticular Disease}

While the process of diverticula formation and the susceptibility of diverticula to both inflammation and bleeding per se are evident for obvious reasons (see above), the underlying pathomechanisms which trigger the development of diverticula are not yet fully clarified. In fact, the pathogenesis appears to be multifactorial and involves both morphologic and functional alterations of the bowel wall which may further explain the initiation of the disease (table 1) [20].

\section{Alterations of Enteric Connective Tissue}

Evidence of connective tissue alterations promoting the development of diverticula has been derived from those conditions in which the composition and metabolism of the connective tissue matrix are congenitally disturbed. Thus, the incidence and early onset of diverticulosis is significantly increased in patients with Ehlers-Danlos syndrome (gene mutations for collagen) or Marfan syndrome (gene mutation for fibrillin) [21]. The general weakening of connective tissue compounds with increasing age would also explain the widespread distribution of diverticulosis in the elderly. From hernia research, a hypothesis has been raised suggesting that the commonly encountered coincidence of abdominal wall/inguinal hernia, cholecystolithiasis, and colonic diverticulosis (Saint's triad) as well as aortic aneurysm, lung emphysema, and pelvic organ prolapse may be due to a systemic connective tissue disorder [22].

Specimens obtained from diverticular disease showed a shift from stable collagen type I towards the less tensile collagen type III and alterations of enzymes involved in the connective tissue metabolism (e.g. matrix metalloproteinases, tissue inhibitors) [23, 24]. Apart from altered collagen fibers, elastic fibers have also been shown to be increased, in particular within the longitudinal muscle layer ('elastosis coli'), thereby leading to enhanced longitudinal contraction and excess of mucosal tissue prone to herniation [25, 26]. Calculation of the connective tissue index revealed that in the longitudinal muscle layer the relative portion of connective tissue 
Table 1. Structural and functional alterations of the bowel wall in diverticular disease

\begin{tabular}{ll}
\hline Enteric connective tissue & increased overall connective tissue content \\
& altered composition of collagen types \\
& increased cross-linking of collagen fibers \\
& increased elastin fibers ('elastosis coli') \\
& disturbed connective tissue metabolism \\
& thickening of circular and longitudinal muscle ('myochosis coli') \\
Enteric musculature & deranged architecture of muscle fibers \\
& focal loss of myofilaments \\
& fibrotic degeneration \\
& oligo-neuronal hypoganglionosis \\
Enteric nervous system & imbalance of neurotransmitters/receptors \\
& deficiency in neurotrophic factors \\
& nerve fiber remodeling \\
increased pain-mediating neurotransmitter systems & loss of interstitial cells of Cajal (intestinal pacemakers) \\
In vitro intestinal motility & increased intraluminal pressure \\
increased motility index & increased high-amplitude propagated contractions \\
retrograde propagations & visceral hypersensitivity \\
altered spontaneous contractility pattern \\
decreased relaxation due to impaired nitrergic input \\
increased contraction due to enhanced cholinergic input \\
\\
\end{tabular}

elements was significantly increased compared to controls [27] (fig. 2a, b). Moreover, the overall content of collagen fibers as well as the degree of collagen cross-linking were higher in specimens from diverticular disease compared to controls [25, 26, 28]. It is suggested that connective tissue alterations on the one hand impair the flexibility and resilient forces of the gut wall and on the other hand enlarge and further soften the weak spots (loci minoris resistentiae), thereby promoting the development of diverticula.

\section{Alterations of Enteric Musculature}

One of the most consistent histopathologic features in diverticular disease is the thickening of the muscle coat affecting both the circular and longitudinal muscle layer [26, 27, 29] (fig. 2c, d). The muscular tissue architecture is disturbed and characterized by aberrant muscle bundles of unordered direction and focal replacement of myocytes by connective tissue. The myostatic muscular thickening ('myochosis coli') appears to originate from hypertrophy of myocytes and additional deposits of connective tissue. Although the muscle coat is morphologically thickened, the content of functionally relevant myofilaments is partly reduced. An essential myofilament component, smooth muscle myosin heavy chain, was found to be decreased both at the gene expression and protein level in the enteric musculature of patients with diverticular disease [27]. This finding further questions the functional integrity of the smooth muscle contractile apparatus in spite of the overall hypertrophy of the muscle coat.

\section{Alterations of the Enteric Nervous System}

First evidence for structural changes in the enteric nervous system emerged five decades ago, when Macbeth and Hawthorn [30] reported enlarged and ectopically located myenteric ganglia in diverticular disease suggesting a 'neuromuscular derangement'. Involvement of the enteric nervous system was confirmed in subsequent studies which mainly described a reduced ganglionic and neuronal number in patients with diverticular disease compared to controls [31-33] (fig. 2e, f). Other studies could not observe major neural alterations while others showed a decreased amount of enteric glial cells and intestinal pacemaker cells (interstitial cells of Cajal) [34-36]. A possible explanation for the decline of both enteric nerve and glial cells as evidenced by morphometric quantification might be a deficiency of neurotrophic factors responsible for the development and maintenance of the enteric nervous system, such as the glial cell line-derived neurotrophic factor (GDNF). A deficit of GDNF and its receptors was only recently reported in the muscularis propria obtained from patients with diverticular disease compared to controls [37]. As the GDNF system promotes growth and differentiation as well as synaptic plasticity of the enteric nervous system $[38,39]$, it is conceivable that decreased expression of the GDNF system impairs both the maintenance of the enteric nervous system and adequate enteric neurotransmission.

Other factors contributing to a disturbed neurotransmission involve alterations of neurotransmitters released by enteric nerve cells. The imbalance of the neurotransmitter spectrum reported in diverticular disease involves both excitatory (e.g. acetylcholine, substance P) and inhibitory (e.g. nitric oxide, vasoactive intestinal polypeptide) agents [25, 40-43]. Moreover, neurotransmitter receptors essential for mediating intestinal motility are obviously affected in diverticular disease, e.g. down-regulation of serotonin receptor 4 (5HT-4R) and up-regulation of muscarinic receptor 3 (M3) $[40,44]$. A significant decrease in SERT transcript levels was 
Fig. 2. Alterations of the $\mathbf{a}, \mathbf{b}$ enteric connective tissue, $\mathbf{c}, \mathbf{d}$ enteric musculature, and $\mathbf{e ,} \mathbf{f}$ enteric nervous system in diverticular disease (DD) compared to controls. Within the muscle layers (red colored tissue), the relative portion of connective tissue (green colored area) is significantly increased in $\mathbf{b}$ DD compared to $\mathbf{a}$ controls. Both the circular (CM) and longitudinal (LM) muscle layer are considerably thickened in $\mathbf{d}$ DD compared to $\mathbf{c}$ controls. Enteric ganglia of the myenteric plexus (MP) located between the CM and LM exhibit a significantly decreased nerve cell (NC) density in $\mathbf{f} \mathrm{DD}$ compared to e controls. a, b Azan staining with false-color conversion of connective tissue elements (modified from [27]); c, d Azan staining, (modified from [27]); e, f anti-Hu C/D immunohistochemistry, hematoxylin counterstain (modified from [33]).
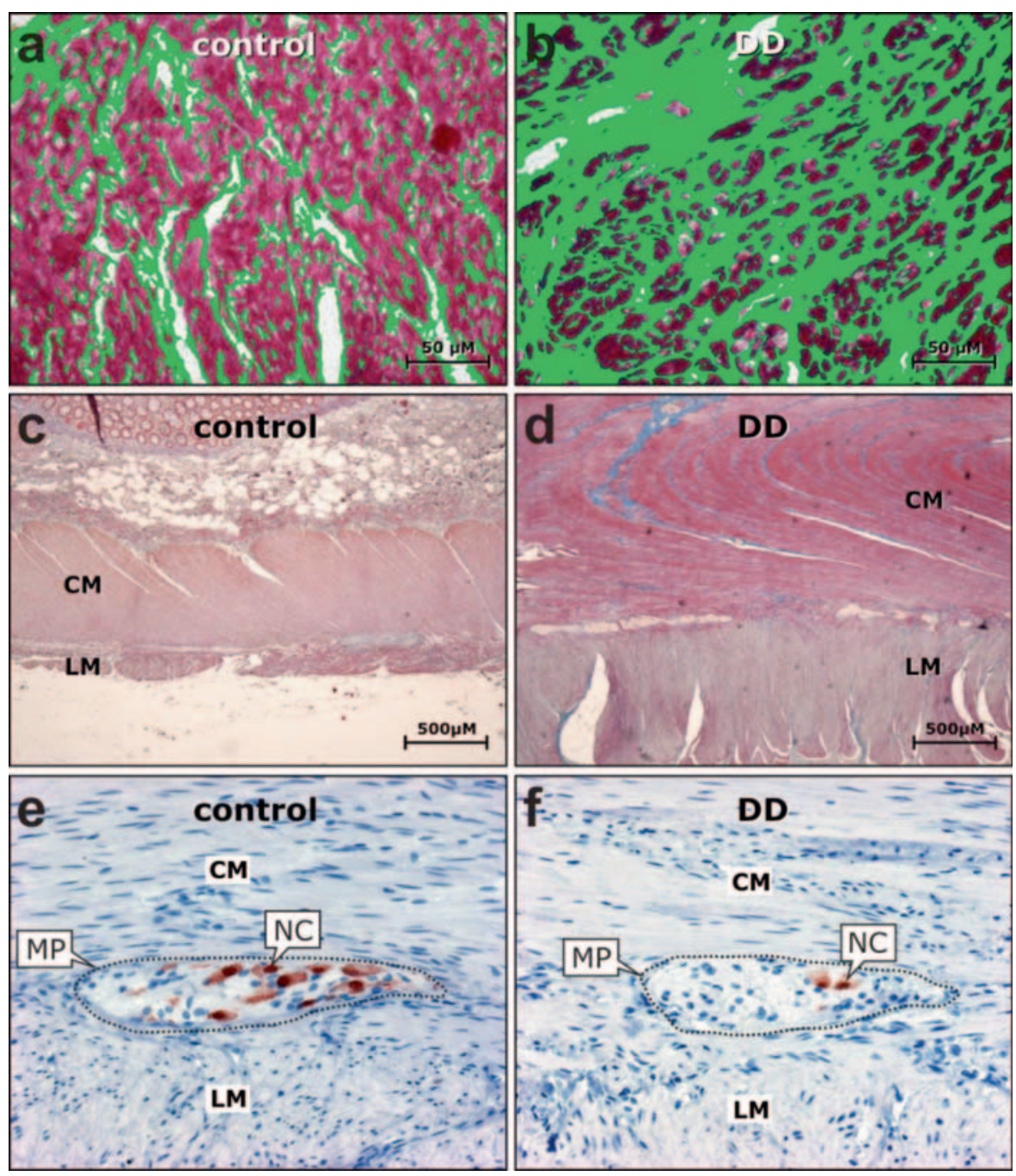

found in the mucosa of patients with a recent history of acute diverticulitis [45]. Alterations of enteric neurotransmitters have also been implicated in the generation of symptoms in chronic recurrent stages of diverticular disease. The persistent abdominal pain has been attributed to an increase in pain-mediating neurotransmitters, e.g. galanin, neuropeptide $\mathrm{K}$, and enteric nerve fiber remodeling most likely due to postinflammatory reactions - similar to irritable bowel syndrome $[46,47]$.

In summary, several of the histopathologic features described in gastrointestinal neuromuscular pathology underlying intestinal motility disorders [48] have also been found in diverticular disease. This suggests that altered intestinal innervation patterns may lead to intestinal motility disturbances which trigger the development of diverticula.

\section{Alterations in Intestinal Motility}

In accordance to the enteric neuromuscular pathology observed in diverticular disease, at least some of the patients with diverticular disease also exhibit disturbances of intestinal motility both under in vivo conditions and in in vitro studies. Organ bath experiments on isolated intestinal smooth muscle strips revealed abnor- mal spontaneous contractility patterns as well as altered responses after exposure to excitatory and inhibitory neurotransmitters or agonists. Most studies have found a reduced relaxation capacity of diverticular specimens due to an impaired nitrergic neurotransmitter system $[10,25,41]$, except for one study reporting increased nitric oxide-mediated responses [49]. Conversely, responses to electrical field stimulation and cholinergic stimulation were generally enhanced in diverticular disease resulting in more pronounced contractions $[10,35]$. Interestingly, no differences were found between left-sided and right-sided diverticular disease. Furthermore, in specimens from diverticular disease, endocannabinoids were significantly less potent in inhibiting contraction responses [50], whereas the tachykinergic contractile activity was substantially increased by cyclooxygenase [51].

More recent data derived from organ bath techniques confirmed a series of earlier in vivo studies showing an altered colonic motility pattern evidenced by manometric techniques. Patients with diverticular disease exhibited increased contractile activity and intraluminal pressure under resting conditions and - more consistently - after stimulation by meals or pharmacologic agents [52-57]. However, other studies could not confirm these colonic 
motor disturbances suggesting that not all patients with diverticular disease are equally affected [58, 59]. Recent studies using 24-h manometry could monitor the intestinal motility pattern over longer time periods and found increased motility indices, enhanced high-amplitude propagated contractions with painful sensations, as well as abnormal retrograde propagations [60, 61]. Barostat examinations revealed a heightened perception of distention in symptomatic diverticular disease. This visceral hypersensitivity was not only recorded in the diverticula-bearing sigmoid but also in the rectum [62].

\section{Conclusion}

In spite of the wide distribution and considerably high morbidity of diverticular disease, the pathogenesis is not yet completely clarified. Apparently, up to now a 'causa prima' is not identifiable, as multiple etiologic factors are claimed to trigger the development of diverticula. Besides traditional pathogenetic concepts including lifestyle factors (e.g. low-fiber diet, obesity, reduced physical activ- ity), connective tissue weakness, and muscular thickening, novel aspects have been introduced complementing the current knowledge. Recent studies have given evidence that intestinal motility disturbances frequently observed in diverticular disease are paralleled by intestinal innervation disorders both at the structural and the functional level. Thus, it is conceivable that an impaired enteric neurotransmission may induce abnormal intestinal contraction patterns leading to high pressure zones and subsequent herniation of the mucosal/submucosal layer through preformed loci minoris resistentiae. Although this pathogenetic cascade is intriguing, it remains to be determined whether the enteric neuromuscular changes occur consistently before the formation of colonic diverticula or are secondary to inflammatory events during and after episodes of diverticulitis.

\section{Disclosure Statement}

The authors declare no conflict of interest.

\section{References}

1 Sandler RS, Everhart JE, Donowitz M, Adams E, Cronin K, Goodman C, Gemmen E, Shah S, Avdic A, Rubin R: The burden of selected digestive diseases in the United States. Gastroenterology 2002;122:15001511.

2 Leifeld L, Germer CT, Bohm S, Dumoulin FL, Hauser W, Kreis M, Labenz J, Lembcke B, Post S, Reinshagen M, Ritz JP, Sauerbruch T, Wedel T, von Rahden B, Kruis W: S2k guidelines diverticular disease/diverticulitis (Article in German). Z Gastroenterol 2014;52: $663-710$.

3 Schumpelick V, Koch G: The role of incomplete diverticle for diverticular disease (author's transl) (Article in German). Langenbecks Arch Chir 1974;336:1-14.

4 Becker V: Diverticulosis. Anatomical aspects (Article in German). Radiologe 1983;23:533-539.

5 Stollman N, Raskin JB: Diverticular disease of the colon. Lancet 2004;363:631-639.

6 Lee YS: Diverticular disease of the large bowel in Singapore. An autopsy survey. Dis Colon Rectum 1986; 29:330-335

7 Parks TG: Natural history of diverticular disease of the colon. Clin Gastroenterol 1975;4:53-69.

8 Sugihara K, Muto T, Morioka Y, Asano A, Yamamoto T: Diverticular disease of the colon in Japan. A review of 615 cases. Dis Colon Rectum 1984;27:531-537.

9 Nakaji S, Danjo K, Munakata A, Sugawara K, MacAuley D, Kernohan G, Baxter D: Comparison of etiology of right-sided diverticula in Japan with that of leftsided diverticula in the West. Int J Colorectal Dis 2002; 17:365-373.

10 Tomita R: Are there any functional differences of the enteric nervous system between the right-sided diverticular colon and the left-sided diverticular colon? An in vitro study. Int J Colorectal Dis 2014;29:571-577.

11 Goldstein NS, Ahmad E: Histology of the mucosa in sigmoid colon specimens with diverticular disease: observations for the interpretation of sigmoid colonoscopic biopsy specimens. Am J Clin Pathol 1997;107: 438-444.
2 Von Rahden BH, Germer CT: Pathogenesis of colonic diverticular disease. Langenbecks Arch Surg 2012;397: 1025-1033.

13 West AB, Losada M: The pathology of diverticulosis coli. J Clin Gastroenterol 2004;38:S11-16.

14 Peppercorn MA: The overlap of inflammatory bowel disease and diverticular disease. J Clin Gastroenterol 2004;38:S8-10.

15 Haboubi NY, Alqudah M: Pathology and pathogenesis of diverticular disease and patterns of colonic mucosal changes overlying the diverticula. Dig Dis 2012;30:2934.

16 Tursi A, Elisei W, Giorgetti GM, Inchingolo CD, Nenna R, Picchio M, Brandimarte G: Segmental colitis associated with diverticulosis: a 5-year follow-up. Int J Colorectal Dis 2012;27:179-185.

17 Lewis M: Bleeding colonic diverticula. J Clin Gastroenterol 2008;42:1156-1158.

18 Meyers MA, Alonso DR, Gray GF, Baer JW: Pathogen esis of bleeding colonic diverticulosis. Gastroenterology 1976;71:577-583.

19 Strate LL, Liu YL, Aldoori WH, Syngal S, Giovannucci EL: Obesity increases the risks of diverticulitis and diverticular bleeding. Gastroenterology 2009;136:115122.e1.

20 Simpson J, Scholefield JH, Spiller RC: Pathogenesis of colonic diverticula. Br J Surg 2002;89:546-554.

21 Santin BJ, Prasad V, Caniano DA: Colonic diverticulitis in adolescents: an index case and associated syndromes. Pediatr Surg Int 2009;25:901-905.

22 Read RC: Herniology: past, present, and future. Hernia 2009; 13:577-580.

23 Bode MK, Karttunen TJ, Makela J, Risteli L, Risteli J: Type II and III collagens in human colon cancer and diverticulosis. Scand J Gastroenterol 2000;35:747-752.

24 Rosemar A, Ivarsson ML, Borjesson L, Holmdahl L: Increased concentration of tissue-degrading matrix metalloproteinases and their inhibitor in complicated diverticular disease. Scand J Gastroenterol 2007;42: 215-220.
25 Golder M, Burleigh DE, Ghali L, Feakins RM, Lunniss PJ, Williams NS, Navsaria HA: Longitudinal muscle shows abnormal relaxation responses to nitric oxide and contains altered levels of nos 1 and elastin in uncomplicated diverticular disease. Colorectal Dis 2007; 9:218-228.

26 Whiteway J, Morson BC: Elastosis in diverticular disease of the sigmoid colon. Gut 1985;26:258-266.

27 Hellwig I, Bottner M, Barrenschee M, Harde J, Egberts $\mathrm{JH}$, Becker T, Wedel T: Alterations of the enteric smooth musculature in diverticular disease. J Gastroenterol 2014;49:1241-1252.

28 Wess L, Eastwood MA, Wess TJ, Busuttil A, Miller A: Cross linking of collagen is increased in colonic diverticulosis. Gut 1995;37:91-94.

29 Hughes LE: Postmortem survey of diverticular disease of the colon. II. The muscular abnormality of the sigmoid colon. Gut 1969;10:344-351.

30 Macbeth WA, Hawthorne JH: Intramural ganglia in diverticular disease of the colon. J Clin Pathol 1965;18: $40-42$.

31 Deduchovas O, Saladzinskas Z, Tamelis A, Pavalkis D, Pauziene N, Pauza DH: Morphologic pattern of myenteric neural plexus in colonic diverticular disease. A whole-mount study employing histochemical staining for acetylcholinesterase. Ann Anat 2008;190:525-530.

32 Iwase H, Sadahiro S, Mukoyama S, Makuuchi H, Yasuda M: Morphology of myenteric plexuses in the human large intestine: comparison between large intestines with and without colonic diverticula. J Clin Gastroenterol 2005;39:674-678.

33 Wedel T, Busing V, Heinrichs G, Nohroudi K, Bruch HP, Roblick UJ, Bottner M: Diverticular disease is associated with an enteric neuropathy as revealed by morphometric analysis. Neurogastroenterol Motil 2010;22:407-414, e93-94.

34 Bassotti G, Battaglia E, Bellone G, Dughera L, Fisogni S, Zambelli C, Morelli A, Mioli P, Emanuelli G, Villanacci V: Interstitial cells of Cajal, enteric nerves, and glial cells in colonic diverticular disease. J Clin Pathol 2005;58:973-977. 
35 Gallego D, Espin F, Mikulka J, Smirg O, Gil V, Faundez-Zanuy M, Jimenez M, Clave P: In vitro motor patterns and electrophysiological changes in patients with colonic diverticular disease. Int J Colorectal Dis 2013; 28:1413-1422.

-36 Vuong NP, Sezeur A, Balaton A, Malafosse M, Camilleri JP: Myenteric plexuses and colonic diverticulosis: results of a histological study (Article in French). Gastroenterol Clin Biol 1985;9:434-436.

-37 Böttner M, Barrenschee M, Hellwig I, Harde J, Egberts JH, Becker T, Zorenkov D, Schafer KH, Wedel T: The GDNF system is altered in diverticular disease - implications for pathogenesis. PLoS One 2013;8:e66290.

38 Barrenschee M, Bottner M, Hellwig I, Harde J, Egberts JH, Becker T, Wedel T: Site-specific gene expression and localization of growth factor ligand receptors RET, GFR $\alpha 1$ and GFR $\alpha 2$ in human adult colon. Cell Tissue Res 2013;354:371-380.

39 Bottner M, Harde J, Barrenschee M, Hellwig I, Vogel I, Ebsen M, Wedel T: GDNF induces synaptic vesicle markers in enteric neurons. Neurosci Res 2013;77: 128-136.

40 Golder M, Burleigh DE, Belai A, Ghali L, Ashby D, Lunniss PJ, Navsaria HA, Williams NS: Smooth muscle cholinergic denervation hypersensitivity in diverticular disease. Lancet 2003;361:1945-1951.

41 Tomita R, Fujisaki S, Tanjoh K, Fukuzawa M: Role of nitric oxide in the left-sided colon of patients with diverticular disease. Hepatogastroenterology 2000;47: 692-696.

42 Milner P, Crowe R, Kamm MA, Lennard-Jones JE, Burnstock G: Vasoactive intestinal polypeptide levels in sigmoid colon in idiopathic constipation and diverticular disease. Gastroenterology 1990;99:666-675.

43 Tomita R, Munakata K, Aoki N, Tanjoh K, Kurosu Y: A study on the peptidergic nerves (VIP, substance P) in the colon of patients with diverticular disease. Regul Pept 1993;46:244-246.

44 Böttner M, Barrenschee M, Hellwig I, Harde J, Egberts $\mathrm{JH}$, Becker T, Zorenkov D, Wedel T: The enteric serotonergic system is altered in patients with diverticular disease. Gut 2013;62:1753-1762.
45 Costedio MM, Coates MD, Danielson AB, Buttolph TR 3rd, Blaszyk HJ, Mawe GM, Hyman NH: Serotonin signaling in diverticular disease. J Gastrointest Surg 2008;12:1439-1445.

46 Humes DJ, Simpson J, Smith J, Sutton P, Zaitoun A, Bush D, Bennett A, Scholefield JH, Spiller RC: Visceral hypersensitivity in symptomatic diverticular disease and the role of neuropeptides and low grade inflammation. Neurogastroenterol Motil 2012;24:318-e163.

47 Simpson J, Sundler F, Humes DJ, Jenkins D, Scholefield JH, Spiller RC: Post inflammatory damage to the enteric nervous system in diverticular disease and its relationship to symptoms. Neurogastroenterol Motil 2009;21:847-e58.

48 Knowles CH, De Giorgio R, Kapur RP, Bruder E, Farrugia G, Geboes K, Lindberg G, Martin JE, Meier-Ruge WA, Milla PJ, Smith VV, Vandervinden JM, Veress B, Wedel T: The London Classification of gastrointestinal neuromuscular pathology: report on behalf of the Gastro 2009 International Working Group. Gut 2010;59: 882-887.

49 Espin F, Rofes L, Ortega O, Clave P, Gallego D: Nitrergic neuro-muscular transmission is up-regulated in patients with diverticulosis. Neurogastroenterol Motil 2014;26:1458-1468.

50 Guagnini F, Valenti M, Mukenge S, Matias I, Bianchetti A, Di Palo S, Ferla G, Di Marzo V, Croci T: Neural contractions in colonic strips from patients with diverticular disease: role of endocannabinoids and substance P. Gut 2006;55:946-953.

51 Fornai M, Colucci R, Antonioli L, Ippolito C, Segnani C, Buccianti P, Marioni A, Chiarugi M, Villanacci V, Bassotti G, Blandizzi C, Bernardini N: Role of cyclooxygenase isoforms in the altered excitatory motor pathways of human colon with diverticular disease. Br J Pharmacol 2014;171:3728-3740.

52 Painter NS, Truelove SC, Ardran GM, Tuckey M: Effect of morphine, prostigmine, pethidine, and probanthine on the human colon in diverticulosis studied by intraluminal pressure recording and cineradiography. Gut 1965;6:57-63.
3 Parks TG, Connell AM: Motility studies in diverticular disease of the colon. Gut 1969;10:534-542.

54 Ritchie JA: Movement of segmental constrictions in the human colon. Gut 1971;12:350-355.

55 Cortesini C, Pantalone D: Usefulness of colonic motility study in identifying patients at risk for complicated diverticular disease. Dis Colon Rectum 1991;34:339_ 342

56 Suchowiecky M, Clarke DD, Bhasker M, Perry RJ, Snape WJ Jr: Effect of secoverine on colonic myoelectric activity in diverticular disease of the colon. Dig Dis Sci 1987;32:833-840.

57 Trotman IF, Misiewicz JJ: Sigmoid motility in diverticular disease and the irritable bowel syndrome. Gut 1988;29:218-222.

58 Katschinski M, Lederer P, Ellermann A, Ganzleben R, Lux G, Arnold R: Myoelectric and manometric patterns of human rectosigmoid colon in irritable bowel syndrome and diverticulosis. Scand J Gastroenterol 1990;25:761-768.

59 Leandro PA, Cecconello I, Habr-Gama A, de Olivereira e Silva A, Pontes JF: Gastrointestinal motility in normal subjects and patients with diverticulosis of the colon. Arq Gastroenterol 1984;21:157-163.

60 Bassotti G, Battaglia E, De Roberto G, Morelli A, Tonini M, Villanacci V: Alterations in colonic motility and relationship to pain in colonic diverticulosis. Clin Gastroenterol Hepatol 2005;3:248-253.

61 Bassotti G, Battaglia E, Spinozzi F, Pelli MA, Tonini M: Twenty-four hour recordings of colonic motility in patients with diverticular disease: evidence for abnormal motility and propulsive activity. Dis Colon Rectum 2001;44:1814-1820.

62 Clemens CH, Samsom M, Roelofs J, van Berge Henegouwen GP, Smout AJ: Colorectal visceral perception in diverticular disease. Gut 2004;53:717-722. 